\title{
Facemask headache: a new nosographic entity among healthcare providers in COVID-19 era
}

\author{
Laura Rapisarda $^{1}$ - Michele Trimboli ${ }^{1}$ (D) Francesco Fortunato $^{1} \cdot$ Antonio De Martino $^{1} \cdot$ Oreste Marsico ${ }^{1}$. \\ Giulio Demonte ${ }^{1} \cdot$ Antonio Augimeri $^{2} \cdot$ Angelo Labate $^{1} \cdot$ Antonio Gambardella $^{1}$
}

Received: 24 October 2020 / Accepted: 18 January 2021 / Published online: 27 January 2021

(C) Fondazione Società Italiana di Neurologia 2021

\begin{abstract}
Background SARS-CoV-2 is a novel infectious agent causing coronavirus disease 2019, which has been declared as pandemic in March 2020. Personal protective equipment has been mandatory for healthcare workers in order to contain the outbreak of pandemic disease. Mild neurological disturbances such as headache have been related to the extensive utilization of facemask. This study aims to examine headache variations related to the intensive utilization of facemask among a cohort of healthcare professionals in a setting of low-medium risk of exposure to SARS-CoV-2.

Methods This is a cross-sectional study among healthcare providers from different hospital and clinics in Italy. Each participant completed a specifically designed self-administered questionnaire. Headache features and outcome measures' change from baseline were evaluated over a 4-month period, in which wearing facemask has become mandatory for Italian healthcare workers. Results A total of 400 healthcare providers completed the questionnaire, 383 of them met the inclusion criteria. The majority were doctors, with a mean age of $33.4 \pm 9.2$ years old. Among 166/383 subjects, who were headache free at baseline, $44(26.5 \%)$ developed de novo headache. Furthermore, 217/383 reported a previous diagnosis of primary headache disorder: 137 were affected by migraine and 80 had tension-type headache. A proportion $(31.3 \%)$ of these primary headache sufferers experienced worsening of their pre-existing headache disorder, mainly for migraine frequency and attack mean duration.

Conclusions Our data showed the appearance of de novo associated facemask headache in previous headache-free subjects and an exacerbation of pre-existing primary headache disorders, mostly experienced by people with migraine disease.
\end{abstract}

Keywords Migraine $\cdot$ Tension-type headache $\cdot$ Allodynia

\section{Introduction}

Coronavirus disease 2019 (COVID-19) is an acute infection of the respiratory tract emerged in late 2019 from the city of Wuhan in China and rapidly spread to other countries worldwide [1]. On March 11, World Health Organization (WHO) declared COVID-19 outbreak a global pandemic [1-3]. To date, there

The present study followed the Headache and Migraine Disease Language and Image Guide by CHAMP (https:/headachemigraine.org/ wp-content/uploads/CHAMP-Language-Guide-Web.pdf)

Michele Trimboli

trimboli.michele@gmail.com

1 Institute of Neurology, Department of Medical and Surgical Sciences, AOU Mater Domini - Magna Græcia University, V.le Europa, 88100 Catanzaro, Italy

2 Biotecnomed S.CaR.L., Catanzaro, Italy are nearly 87.4 million confirmed COVID-19-affected patients worldwide. The first imported cases in Italy were on 23 January 2020 in a couple of Chinese tourists [4], and it is now reaching the number of 2.2 million, with around 77,000 deaths [5]. On March 8, 2020, the Italian Government implemented extraordinary measures to limit viral transmission, such as city lockdowns and movement restriction, initially in the region of Lombardy, then extended to the entire nation (phase I) [6]. On May 16, 2020, the Italian Government declared the suspension of the extraordinary measures, but people are suggested to keep social distancing and wear facemask (phase II) [7]. SARS-CoV-2, like other coronaviruses, spread by respiratory droplets; therefore, personal protective equipment (PPE) has become mandatory for healthcare workers while attending to patients, in order to contain the outbreak of pandemic disease [8]. In particular, both surgical and close-fitting N95 facemasks create a barrier between individuals limiting the aerosol spread of viruses [8]. Thus, in clinical practice, masking has become a standard among 
frontline healthcare personnel against COVID-19 [9]. Wearing PPE for a long period led to physical distress [10] and could induce subjective negative symptoms, such as dizziness, perceived shortness of air, and headache [11]. During the 2003 SARS epidemic, researchers highlighted the association between complaints of new-onset headache and use of N95 facemask in healthcare providers working in high-risk areas [12]. A recent study described the developing of PPE-associated headache in frontline medical and paramedical staff during COVID-19 pandemic, especially in emergency department professionals who combined daily use of N95 facemask and protective eyewear [13]. Moreover, a symptoms' worsening of pre-existing primary headaches due to continuative masking has been also described [13]. Authors showed that PPE-associated headache fulfilled the International Classification of Headache Disorders (ICHD-3) criteria for external-compression headache $(\mathrm{ECH})$, defined as "headache starting within one hour from compression of pericranial soft tissues and resolving within one hour after external compression is relieved" [14]. The aim of our study was to evaluate the impact of facemask wearing on headache in two different categories of healthcare workers: subjects with and without pre-existing diagnosis of primary headache disorder.

\section{Methods}

This cross-sectional study has been conducted during Italian phase II. We enrolled different healthcare professionals including doctors, nurses, healthcare assistants, and other paramedical staff such as technicians, physiotherapists, and psychologists, from numerous Italian hospitals and clinics. Written informed consent was obtained from each participant and the study was approved by the local institutional review board. Each enrolled subject completed a specifically designed self-administered questionnaire written in Italian language. Participants were directly invited to complete the questionnaire form throughout their personal web-email. The questionnaire consisted in 5 query sections: I-demographics (gender, age, occupation), comorbidities, and type of work during the COVID-19 Italian phase II: active or smart working; II-phenotype, associated features, outcome measures, related disability of any primary headache disorder diagnosed before COVID-19 outbreak; III- phenotype, associated features, outcome measures, related disability of any headache disorder experienced after mandatory healthcare workers facemasking during phase II; IV_-participants' personal impression about the impact of face-masking on headache disorder; $\mathrm{V}$-facemask use information (number of weekly work hours, number of daily hours wearing facemask, type of facemask used, type of facemask elastic head straps: occipital or preauricular). We excluded subjects who keep performing smart working after lockdown period; only active workers have been included in the study. Afterwards, we excluded participants with comorbidities likely to be cause of secondary headaches. We evaluated headache profile and outcome measures over a 30-day period before the beginning of lockdown period (baseline, $\mathrm{T} 0$ ) and during the first 4 months of Italian phase II (T1: average of four months). To assess headache profile change from $\mathrm{T} 0$ to $\mathrm{T} 1$, different patient-reported outcome measures have been used. The outcome measures (headache days (HD), migraine days (MD), migraine-like day (MLD), average headache severity (AHS)) were retrospectively collected, through the questionnaire, in line with the Initiative on Methods, Measurement, and Pain Assessment in Clinical Trials (IMMPACT) [16]. Localization (unilateral or bilateral), pain quality (throbbing, pressing or tightening and stabbing), headache duration (hours), and AHS through numerical rating scale (NRS - 0 (no head pain) to 10 (most severe head pain ever experienced)) were recorded. A headache day (HD) was considered a day with headache lasting for $\geq 4 \mathrm{~h}$ and with a severity of $\geq 4 / 10$ on NRS. A de novo headache was recorded whether at least one HD was reported at T1. A migraine day (MD) was defined according to the IHS migraine classification criteria [15]. Associated symptoms such as phonophobia/photophobia and nausea/vomit have also been recorded. A migraine-like day (MLD) was defined as a day in which the subject reported headache with associated symptoms which did not fulfill IHS criteria for MD. Headache-related disability change between $\mathrm{T} 0$ and $\mathrm{T} 1$ was collected using headache impact test (HIT-6) [17]. The 12item allodynia symptom checklist (ASC-12) has been used to score allodynia at $\mathrm{T} 0$ and $\mathrm{T} 1$; moreover, a supplementary item has been added to the aforementioned scale to assess the impact of elastic head straps on allodynia at T1. A subject was considered allodynic if ASC-12 score was greater than 2 [18]. We also investigated abortive treatment consumption, including non-steroidal anti-inflammatory drugs (NSAIDS; episodic consumption (1-9/month); frequent consumption (10-14/ month); abuse ( $\geq 15 /$ month)), triptans (episodic consumption (1-9/month); abuse ( $\geq 10 /$ month)), and other pain killer drugs (episodic consumption (1-9/month); frequent consumption (10-14/month); abuse ( $\geq 15 /$ month)) used for attempted headache relief. Pre-existing preventive treatments used for primary headache disorders and any preventive treatment switch have been also recorded. Participants' subjective impression about the impact of facemask on headache disorder was evaluated through adaptation of Patient's Global Impression of Change (PGIC) scale: a score of 0 means "no change" and a score of 10 means "dramatic worsening" [20].

\section{Statistical analysis}

Data were collected in a database created ad hoc. Differences in sex distribution and binary variables have been assessed by means of the Fisher's exact test. The variables were tested for 
normal distribution with the Shapiro-Wilk test. Quantitative variables were expressed as mean and standard deviation, and categorical variables as frequencies and percentages. Comparison between groups for age, HD, MD, MLD, headache attack duration, AHS, allodynia, ASC-12, HIT-6, pain killers, preventive treatments, discomfort for elastic head straps, and personal perception of facemask impact on headache was performed with ANOVA followed by pairwise Wilcoxon rank sum test. The statistical significance was set at $p \leq 0.05$. All $p$ values were corrected according to Bonferroni. A multivariate (multiple) linear regression analysis was performed to identify the independent variables associated with the development of de novo facemask headache and/or the worsening of pre-existent primary headache disorders. More to the point, the presence of association between the variables related to the facemask use (hours wearing facemask, type of facemask, type of elastic head straps, facemask impact evaluated trough PGIC adapted scale) and the headache outcome measures' change from T0 to T1 (HD, MD, MLD, AHS, HIT-6, ASC-12, abortive treatment consumption) has been assessed. Statistical analysis was performed with $\mathrm{R}$ Statistical software ( $\mathrm{R}$ for Unix/Linux, version 3.1.1, the $\mathrm{R}$ Foundation for Statistical Computing, Vienna, Austria).

\section{Results}

\section{Demographic features}

We received 400 out of 1000 email forwarded questionnaires completed by healthcare providers from different areas in Italy (see Fig. 1). Seventeen participants have been excluded as they still performing smart working or suffering with comorbidities likely to be cause of secondary headaches. Demographic characteristics of subjects are summarized in Table 1. Among 383 active workers (M/F 134/249), the vast majority were doctors followed by nurses and technicians. Most of participants had a full-time job (20-38 h per week or more). No respondents reported job changes and/or increase in working hours from T0 to T1. Moreover, they declared wearing facemask for an average from 6 to $10 \mathrm{~h}$ a day. The surgical facemask with pre-auricular elastic head straps was the most common type of facemask used (see Table 1). At baseline, $217 / 383$ subjects were affected by a primary headache disorder (headache group (HG)) and 166/383 were headache free (non-headache group (NHG)), suggesting that those with pre-existing headaches were more likely to complete the questionnaire. There were no differences between groups for age $(p=0.428)$, but they differ for sex: subjects of HG group were mainly women $(p \leq 0.001)$. The groups were not different for mean weekly work hours and mean daily hours wearing facemask (see Table 1). To notice that 74/383 participants (19.3\%) declared that they wear facemask for less than $6 \mathrm{~h}$ a day, hence less than a usual 6-h work shift.

\section{Non-headache group}

Among 166 healthcare providers of NHG, a subgroup of 44 subjects $(26.5 \%)$ developed de novo headache disorder (NHG-DN) at T1, whereas the remaining 122 individuals experienced no $\mathrm{T} 0$ to $\mathrm{T} 1$ change in all outcome variables evaluated. In the majority of cases, de novo headache has been described as pressing or tightening pain with bilateral localization and moderate intensity (NRS: $5.8 \pm 1.5$ ). In addition, a proportion of NHG-DN subjects $(19 / 44 ; 43 \%)$ complained mild associated symptoms such as phonophobia or photophobia, nausea, and vomit, and 26/44 (59\%) NHG-DN subjects reported a discomfort for elastic head straps. Moreover, we found out that $17 / 44$ (39\%) of them were allodynic. De novo headache was attributed by 36 out of $46(78.2 \%)$ respondents as "likely" due to facemask (PGIC scale adaptation, mean \pm $\mathrm{SD}=6.5 \pm 2.7)$. All the variables are reported in Table 2 .

\section{Headache group}

Among HG, 137 subjects had a previous diagnosis of migraine (MHG), while 80 reported tension-type headache (TTHG). Clinical features of both these groups are summarized in Table 2. The majority of subjects of both groups complained an episodic headache at baseline (MHG: 78.1\% and TTHG: 93.7\%). In MHG, 51/137 (37.2\%) described a worsening of headache frequency and 30/137 (21.9\%) experienced longer lasting headache. HD, AHS, and disability (HIT-6) score significantly increased at T1. Other parameters such as MD, ASC-12, number of allodynic subjects, pain killers, and preventive treatment use were not substantially modified from T0 to T1, except for triptans' intake which significantly increased at T1 $(p=0.003)$. Differently, in TTHG, 17/80 (21.3\%) experienced a worsening of headache frequency. HD, MLD, and HIT-6 resulted significantly changed from $\mathrm{T} 0$ to $\mathrm{T} 1$. Other outcome measures did not display substantial modification.

\section{Comparison among MHG, TTHG, and NHG-DN groups}

Comparison among groups (MHG, TTHG, and NHG-DN) at $\mathrm{T} 1$ showed that the three groups were significantly different for all outcome measures except for preventive treatment and other pain killer drug consumption ( $p=0.117$ and $p=0.072$ ) Pairwise comparisons revealed that headache profile was similar between TTHG and NHG-DN. Thus, there were no significant differences for headache frequency (see Fig. 2), HD, mean attack duration, MLD, AHS, ASC-12, HIT-6, and triptans' intake between TTHG and NHG-DN, whereas the number of allodynic subjects ( $p=0.039$; see Fig. 3), discomfort for elastic head straps ( $p=0.001)$, and NSAIDS consumption $(p=0.003)$ were significantly different between TTHG and NHG-DN. Overall NHG-DN and MHG perceived a more 


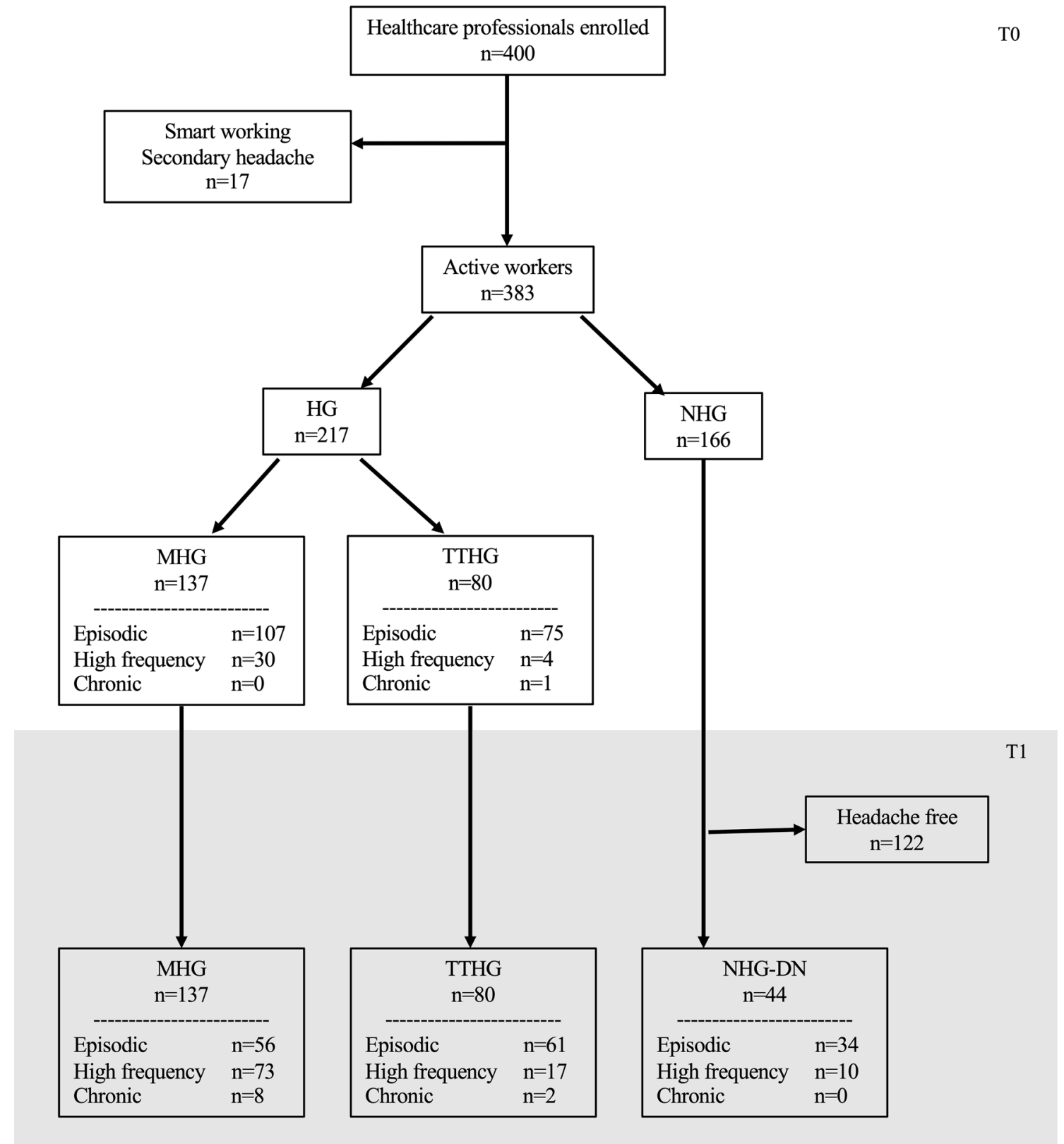

Fig. 1 Flowchart of the assessment of 400 participants. HG, headache group; MHG, migraine-headache group; NHG, non-headache group; NHG-DN, non-headache group-de novo headache sufferers; TTHG,

marked negative impact on headache disorder compared to TTHG $(p=0.005)$.

\section{Multivariate linear regression analysis}

A multivariate (multiple) linear regression was performed to analyze whether the four facemask-related independent variables in the study (hours wearing facemask, type of facemask, type of elastic head straps, facemask impact evaluated trough PGIC adapted scale) were significantly predictive of the T0 to T1 worsening of all headache outcome measures evaluated in tension-type headache group. Headache frequency: (1) episodic: HD 14/month; (2) high frequency: HD 5-14/month; (3) chronic: HD $\geq 15 /$ month

both HG and NHG-DN groups. Despite the model not showing results strong enough to establish a direct cause-and-effect relationship between the facemask use and the measured outcomes score, we found significant relationships between the PGIC score and all the outcome scores in both $\mathrm{HG}$ and NHG-DN groups. In particular, facemask impact evaluated trough PGIC adapted scale shows a relation with HD (coeff $0.63, \pm 0.09, p<0.001$ in HG and coeff $0.46, \pm 0.03, p<0.001$ in NHG-DN), MD (coeff $0.46, \pm 0.08, p<0.001$ in $\mathrm{HG}$ and coeff $0.15, \pm 0.02, p<0.001$ in NHG-DN), NRS (coeff $0.43, \pm$ $0.04, p<0.001$ in HG and coeff $0.68, \pm 0.04, p<0.001$ in 
Table 1 Demographic features of 383 participants

\begin{tabular}{|c|c|c|c|c|}
\hline & Total (383) & NHG (166) & HG (217) & $p$ value \\
\hline Gender $\mathrm{M} / \mathrm{F}$ & $134 / 249$ & $87 / 79$ & $47 / 170$ & $<0.001$ \\
\hline Age, years & $33.4 \pm 9.2$ & $34.8 \pm 10.9$ & $32.2 \pm 7.6$ & 0.428 \\
\hline \multicolumn{5}{|l|}{ Healthcare professionals } \\
\hline Doctors & $299(78.1 \%)$ & $122(73.5 \%)$ & $177(81.6 \%)$ & \multirow[t]{5}{*}{ N/A } \\
\hline Nurses & $42(11.0 \%)$ & $24(14.5 \%)$ & $18(8.3 \%)$ & \\
\hline Healthcare assistants & $12(3.1 \%)$ & $10(6.0 \%)$ & $2(0.9 \%)$ & \\
\hline Technicians & $23(6.0 \%)$ & $7(4.2 \%)$ & $16(7.4 \%)$ & \\
\hline Other paramedical staff & $7(1.8 \%)$ & $3(1.8 \%)$ & $4(1.8 \%)$ & \\
\hline \multicolumn{5}{|l|}{ Weekly work hours } \\
\hline$<20$ h weekly & $9(2.3 \%)$ & $1(0.6 \%)$ & $8(3.7 \%)$ & \multirow[t]{3}{*}{0.653} \\
\hline 20-38 h weekly & $157(41.0 \%)$ & $70(41.9 \%)$ & $87(40.1 \%)$ & \\
\hline$>38 \mathrm{~h}$ weekly & $217(56.7 \%)$ & $95(57.5 \%)$ & $122(56.2 \%)$ & \\
\hline \multicolumn{5}{|l|}{ Daily hours with facemask } \\
\hline $0-2 \mathrm{~h}$ a day & $5(1.3 \%)$ & $2(1.2 \%)$ & $3(1.4 \%)$ & \multirow[t]{7}{*}{0.566} \\
\hline $2-4 \mathrm{~h}$ a day & $19(5.0 \%)$ & $12(7.2 \%)$ & $7(3.2 \%)$ & \\
\hline $4-6 \mathrm{~h}$ a day & $50(13.0 \%)$ & $22(13.3 \%)$ & $28(12.9 \%)$ & \\
\hline $6-8 \mathrm{~h}$ a day & $124(32.4 \%)$ & $50(30.1 \%)$ & $74(34.1 \%)$ & \\
\hline $8-10 \mathrm{~h}$ a day & $95(24.8 \%)$ & $41(24.7 \%)$ & $54(24.9 \%)$ & \\
\hline $10-12 \mathrm{~h}$ a day & $68(17.8 \%)$ & $32(19.3 \%)$ & $36(16.6 \%)$ & \\
\hline$>12 \mathrm{~h}$ a day & $22(5.7 \%)$ & $7(4.2 \%)$ & $15(6.9 \%)$ & \\
\hline \multicolumn{5}{|l|}{ Type of facemask } \\
\hline Surgical facemask & $284(74.2 \%)$ & $123(74.1 \%)$ & $161(74.2 \%)$ & \multirow[t]{3}{*}{0.544} \\
\hline N95 facemask & $96(25 \%)$ & $42(25.3 \%)$ & $54(24.9 \%)$ & \\
\hline Other type of facemask & $3(0.8 \%)$ & $1(0.6 \%)$ & $2(0.9 \%)$ & \\
\hline \multicolumn{5}{|l|}{ Type of elastic head straps } \\
\hline Occipital & $41(10.7 \%)$ & $27(16.3 \%)$ & $14(6.5 \%)$ & \multirow[t]{2}{*}{0.007} \\
\hline Pre-auricular & $342(89.3 \%)$ & $139(83.7 \%)$ & $203(93.5 \%)$ & \\
\hline
\end{tabular}

$F$ female, $M$ male, $M H G$ migraine headache group, $N / A$ not applicable, $N H G$ non-headache group
NHG-DN), HIT-6 (coeff 1.69, $\pm 0.19, p<0.001$ in HG and coeff $2.91, \pm 0.14, p<0.001$ in NHG-DN), and ASC-12 (coeff $0.32, \pm 0.08, p<0.001$ in $\mathrm{HG}$ and coeff $0.32, \pm 0.03, p<0.001$ in NHG-DN). None of the other variables related to the facemask use (hours wearing facemask, type of facemask, type of elastic head straps) was found to predispose to headache outcome measures' change from T0 to T1 in each group $(p>$ $0.05)$.

\section{Discussion}

This study aimed to investigate facemask-associated headache, an important and often undervalued neurological condition which has been related to extensive utilization of facemask during the pandemic. Particularly, our analysis was addressed to a cohort of 383 Italian healthcare professionals, in order to examine this phenomenon in a context characterized by an intensive utilization of surgical or N95 masks during Italian phase II, when the number of COVID- 19-affected subjects dramatically fell but healthcare workers kept wearing facemasks.

Our study showed the appearance of de novo headache in a percentage of subjects $(26.5 \%$, NHG-DN) that were headache free at baseline. De novo headache was mainly described with tension-type features (pressing or tightening quality, bilateral localization, moderate intensity of pain and mild associated symptoms like phonophobia and/or photophobia, nausea, and/or vomit). Moreover, a proportion of de novo headache sufferers reported an abnormal scalp sensitivity or discomfort during headache attacks elicited by non-noxious stimuli (allodynia), including the elastic head straps. PPE-associated headaches were first studied by Lim et al., during southeast Asiatic SARS epidemic in the early 2000s [12]. Stress, mechanical factors, hypoxemia, and hypercapnia have been considered mechanisms involved in the pathogenesis of facemaskassociated headache $[11,19,20]$. A recent study tried to clarify the correlation between increased PPE exposure of frontline healthcare workers during COVID-19 pandemic and development of de novo headaches [13]. This study described de novo PPE-associated headache as a subtype of external-pressure 
Table 2 Clinical features of pre-existing primary headache groups' (MHG and TTHG) subjects at T0-T1, and non-headache group-de novo (NHG$\mathrm{DN})$ subjects at $\mathrm{T} 1$

\begin{tabular}{|c|c|c|c|c|c|c|c|c|}
\hline & \multicolumn{3}{|l|}{ MHG (137) } & \multicolumn{3}{|l|}{ TTHG (80) } & \multirow{2}{*}{$\begin{array}{l}\text { NHG-DN (44) } \\
\text { T1 }\end{array}$} & \multirow[t]{2}{*}{${ }^{\S} p$ value } \\
\hline & $\mathrm{T} 0$ & $\mathrm{~T} 1$ & $p$ value & T0 & $\mathrm{T} 1$ & $p$ value & & \\
\hline Headache days & $3.5 \pm 2.4$ & $5.5 \pm 4.5$ & $<0.001$ & $2.3 \pm 1.9$ & $3.3 \pm 3.4$ & 0.167 & $3.5 \pm 2.6$ & $<0.001$ \\
\hline \multicolumn{9}{|l|}{ Headache frequency } \\
\hline $\begin{array}{l}\text { Episodic ( } 1-4 \text { days/month) } \\
\text { High frequency ( } 5-14 \text { days/month) }\end{array}$ & $\begin{array}{l}107(78.1 \%) \\
30(21.9 \%)\end{array}$ & $\begin{array}{l}56(40.9 \%) \\
73(53.3 \%)\end{array}$ & \multirow[t]{2}{*}{$<0.001$} & $\begin{array}{l}75(93.7 \%) \\
4(5.0 \%)\end{array}$ & $\begin{array}{l}61(76.2 \%) \\
17(21.2 \%)\end{array}$ & \multirow[t]{2}{*}{0.036} & $\begin{array}{l}34(77.3 \%) \\
10(22.7 \%)\end{array}$ & \multirow[t]{2}{*}{0.001} \\
\hline Chronic ( $\geq 15$ days/month) & 0 & $8(5.8 \%)$ & & $1(1.3 \%)$ & $2(2.5 \%)$ & & 0 & \\
\hline Migraine days & $2.5 \pm 1.8$ & $3.9 \pm 3.9$ & 0.650 & 0 & 0 & N/A & 0 & $<0.001$ \\
\hline Migraine-like days & $\mathrm{N} / \mathrm{A}$ & $\mathrm{N} / \mathrm{A}$ & N/A & 0 & $0.6 \pm 2.6$ & $<0.001$ & $1.0 \pm 1.5$ & $<0.001$ \\
\hline \multicolumn{9}{|l|}{ Attack mean duration } \\
\hline $\begin{array}{l}<12 \mathrm{~h} \\
12-24 \mathrm{~h}\end{array}$ & $\begin{array}{l}89(64.9 \%) \\
37(27.0 \%)\end{array}$ & $\begin{array}{l}65(47.4 \%) \\
52(38.0 \%)\end{array}$ & \multirow[t]{4}{*}{0.002} & $\begin{array}{l}60(75.0 \%) \\
13(16.2 \%)\end{array}$ & $\begin{array}{l}56(70.0 \%) \\
17(21.2 \%)\end{array}$ & \multirow[t]{4}{*}{0.287} & $\begin{array}{l}35(79.5 \%) \\
8(18.2 \%)\end{array}$ & \multirow[t]{4}{*}{0.003} \\
\hline $24-48 \mathrm{~h}$ & $6(4.4 \%)$ & $11(8.0 \%)$ & & $6(7.5 \%)$ & $5(6.2 \%)$ & & $1(2.3 \%)$ & \\
\hline $48-72 \mathrm{~h}$ & $5(3.6 \%)$ & $6(4.4 \%)$ & & $1(1.3 \%)$ & $1(1.3 \%)$ & & 0 & \\
\hline$>72 \mathrm{~h}$ & 0 & $3(2.2 \%)$ & & 0 & $1(1.3 \%)$ & & 0 & \\
\hline Average headache severity & $6.0 \pm 1.8$ & $6.6 \pm 1.7$ & 0.021 & $5.2 \pm 1.8$ & $4.9 \pm 2.3$ & 0.717 & $5.8 \pm 1.5$ & $<0.001$ \\
\hline Allodynia (n. subjects) & $58(32.7 \%)$ & $70(40.1 \%)$ & 0.182 & $13(16.2 \%)$ & $17(21.2 \%)$ & 0.543 & $17(38.6 \%)$ & $<0.001$ \\
\hline ASC-12 & $3.0 \pm 3.7$ & $2.8 \pm 3.8$ & 0.171 & $1.0 \pm 1.9$ & $1.3 \pm 2.5$ & 0.810 & $2.1 \pm 2.1$ & $<0.001$ \\
\hline Discomfort for elastic head straps & N/A & $64(46.7 \%)$ & N/A & N/A & $22(27.5 \%)$ & N/A & $26(59.1 \%)$ & $<0.001$ \\
\hline HIT-6 & $59.1 \pm 8.6$ & $62.2 \pm 8.4$ & 0.004 & $51.7 \pm 8.0$ & $54.9 \pm 10.0$ & 0.010 & $58.5 \pm 8.9$ & $<0.001$ \\
\hline \multicolumn{9}{|l|}{ Pain killer use } \\
\hline \multicolumn{9}{|l|}{ NSAIDS } \\
\hline $\begin{array}{l}0 \text { per month } \\
1-9 \text { per month }\end{array}$ & $\begin{array}{l}19(13.9) \\
115(83.9 \%)\end{array}$ & $\begin{array}{l}16(11.7 \%) \\
109(79.6 \%)\end{array}$ & \multirow[t]{3}{*}{0.053} & $\begin{array}{l}12(15 \%) \\
68(85.0 \%)\end{array}$ & $\begin{array}{l}20(25 \%) \\
56(70.0 \%)\end{array}$ & \multirow[t]{3}{*}{0.955} & $\begin{array}{l}19(43.4 \%) \\
24(54.5 \%)\end{array}$ & \multirow[t]{3}{*}{$<0.001$} \\
\hline $10-14$ per month & $3(2.2 \%)$ & $11(8.0 \%)$ & & 0 & $3(3.7 \%)$ & & $1(2.3 \%)$ & \\
\hline$\geq 15$ per month & 0 & $1(0.7 \%)$ & & 0 & $1(1.2 \%)$ & & 0 & \\
\hline \multicolumn{9}{|l|}{ Triptans } \\
\hline 0 per month & $130(94.9 \%)$ & $115(83.9 \%)$ & & $79(98.7 \%)$ & $79(98.7 \%)$ & & $43(87.7 \%)$ & \\
\hline $1-9$ per month & $5(3.6 \%)$ & $12(8.8 \%)$ & \multirow[t]{2}{*}{0.003} & $1(1.3 \%)$ & $1(1.3 \%)$ & \multirow[t]{2}{*}{0.663} & $1(2.3 \%)$ & \multirow[t]{2}{*}{0.006} \\
\hline$\geq 10$ per month & $2(1.5 \%)$ & $10(7.3 \%)$ & & 0 & 0 & & 0 & \\
\hline \multicolumn{9}{|l|}{ Other } \\
\hline $\begin{array}{l}0 \text { per month } \\
1-9 \text { per month }\end{array}$ & $\begin{array}{l}125(91.2 \%) \\
10(7.3 \%)\end{array}$ & $\begin{array}{l}120(87.6 \%) \\
8(5.8 \%)\end{array}$ & \multirow[t]{3}{*}{0.225} & $\begin{array}{l}77(96.2 \%) \\
3(3.8 \%)\end{array}$ & $\begin{array}{l}76(95 \%) \\
4(5.0 \%)\end{array}$ & \multirow[t]{3}{*}{0.387} & $\begin{array}{l}39(88.6 \%) \\
5(11.4 \%)\end{array}$ & \multirow[t]{3}{*}{0.072} \\
\hline $10-14$ per month & 0 & $2(1.5 \%)$ & & 0 & 0 & & 0 & \\
\hline$\geq 15$ per month & $2(1.5 \%)$ & $7(5.1 \%)$ & & 0 & 0 & & 0 & \\
\hline Preventive treatment & $9(6.6 \%)$ & $11(8.0 \%)$ & 0.817 & 0 & $2(3.8 \%)$ & 0.229 & $1(2.3 \%)$ & 0.117 \\
\hline Impact of facemask on headache & N/A & $5.1 \pm 3.1$ & N/A & N/A & $3.8 \pm 3.2$ & N/A & $6.5 \pm 2.7$ & 0.005 \\
\hline
\end{tabular}

$\S_{p}$ value: MHG vs TTHG vs NHG-DN at T1. ASC-12, 12-item allodynia symptom checklist; $M H G$ migraine headache group, $N / A$ not applicable, $N H G$ $D N$ non-headache group-de novo, NSAIDS non-steroidal anti-inflammatory drugs, $T T H G$ tension-type headache group

headache, known as external-compression headache (4.6.1 ICHD-3) [14]. The authors demonstrated that the time interval between donning the N95 facemask (104/128 subjects $(81.3 \%))$ and protective eyewear $(113 / 128$ subjects $(88.0 \%))$ to headache commencement was $<60 \mathrm{~min}$; moreover, a similar time interval of $<60$ min was reported by $95.3 \%$ and $97.7 \%$ of questionnaire respondents for spontaneous headache resolution after removing the N95 facemask and protective eyewear respectively.
It is known that mechanic forces exerted by individual PPE on cranial surface may lead both to local tissue damage and irritation on the superficial sensory nerves innervating cranial and cervical region [21]. Particularly, healthcare professionals undergo an important and prolonged cervical or pre-auricular stress related to elastic straps, which may explain the tensiontype headache developed by the majority of subjects involved in our study [22-24]. Nociceptive input from both great occipital nerve and trigeminal territories converge to the second- 
T0

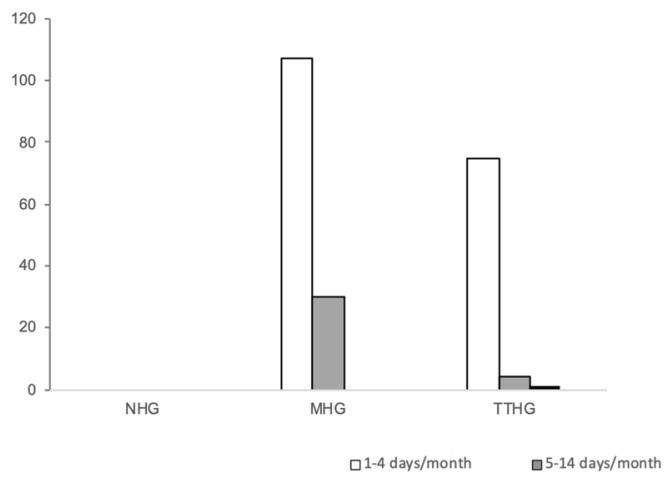

Fig. 2 Headache frequency among three groups from T0 to T1. Among non-headache group (NHG) including headache-free subjects at T0, 44 subjects developed de novo headache at T1: the vast majority developed episodic headache (1-4 days/month). Subjects belonging to migraine-
$\mathrm{T} 1$

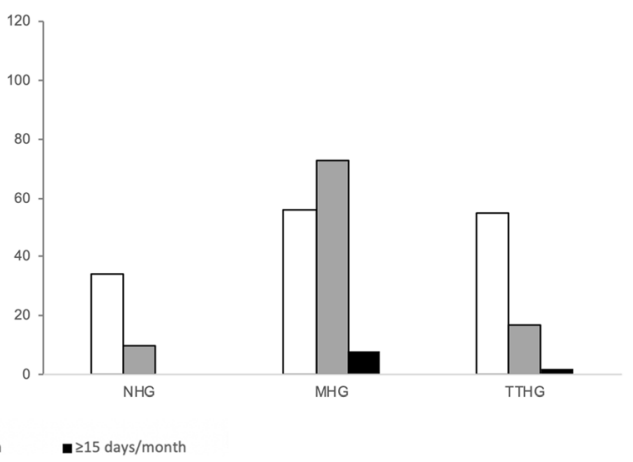

headache group (MHG) and tension-type headache group (TTHG) had mainly episodic headache at T0, and a considerable number of subjects developed a high frequency headache at T1. Moreover, a small number of subjects developed a chronic headache, mainly in $\mathrm{MHG}$
Fig. 3 Allodynia among MHG,

TTHG, and NHG-DN from T0 to

T1. Number of allodynic subjects significantly increased only in non-headache group de novo (NHG-DN) from T0 to T1, whereas there was no statistically significant modification for migraine-headache group (MHG) and tension-type headache group (TTHG) (a). The boxplot revealed that severity of allodynia expressed through ASC-12 score was greater for MHG and NHGDN rather than TTHG at T1 (b) a

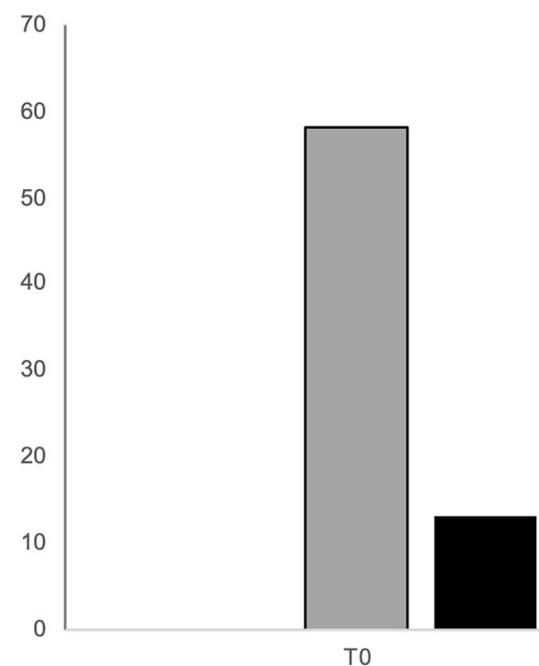

$\square$ NHG-DN

$\square \mathrm{MHG}$

- TTHG

b

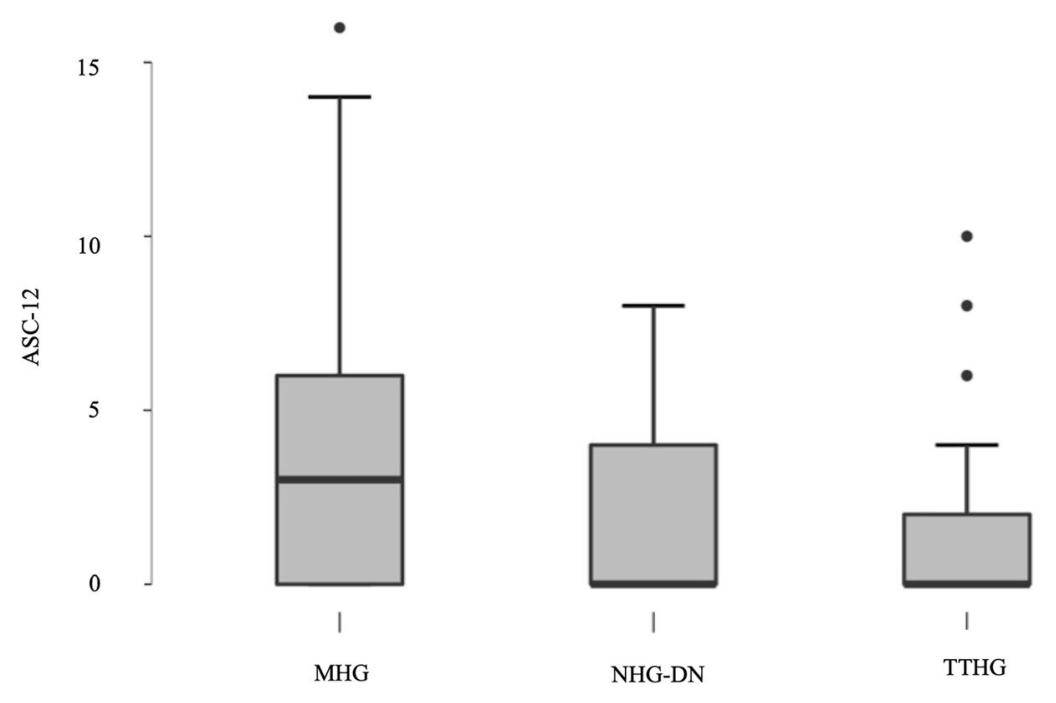


order neurons in the brainstem. Moreover, afferent trigeminal nerves terminate in $\mathrm{C} 2$ spinal segments together with greater occipital nerve afferents [25]. The prolonged mechanical stress on both cervical and pre-auricular regions may cause peripheral sensitization and consequently the activation of trigeminocervical complex, thus stimulating cortical areas triggering headache attacks $[26,27]$. Furthermore, peripheral sensitization is crucial to induce and maintain central sensitization process, which determines temporal, spatial, and threshold changes in pain sensibility, generating pain hypersensitivity and allodinya [28-30].

A previous study has already reported an exacerbation of pre-existing primary headache disorder in a small proportion of subjects, after intense use of PPE during COVID-19 pandemic [13]. Although our study confirms literature data, considering a larger cohort of subjects enrolled, it allowed us to better describe this phenomenon. Our data also revealed headache worsening in subjects with a pre-existing primary headache disorder, both in frequency and mean attack duration, without a substantial modification of headache profile (i.e., pain quality and localization). Particularly participants with a previous diagnosis of tension-type headache (TTHG group) had a significant increase of headache frequency: although the majority continued complaining infrequent episodic headache (HD: 14 days/month), a remarkable percentage of them (16\%) turned to frequent episodic headache (HD: 5-14 days/month-see Fig. 2). In addition, a proportion of tension-type headache subjects reported the appearance/worsening of mild neurologicalassociated symptoms. To notice that TTHG subjects did not experience allodynia.

We hypothesize that, similarly to NHG-DN, facemask wearing might represent a stress factor and mechanical trigger which could induce a worsening of tension-type headache in TTHG group. Several reversible and irreversible risk factors have been reported being responsible for headache chronification [30]. We speculate that sustained mechanical stimulus exerted by elastic straps may cause biochemical alterations which induce a decrease of pain threshold and increased tenderness in these subjects which predispose to headache chronification [31]. Moreover, TTHG participants reported the appearance/worsening of associated symptoms like nausea while wearing facemask. Nausea is commonly reported by migraine sufferers and is associated with impaired functioning and decrease of quality of life. There is some evidence that frequent headache-related nausea may predict chronic headache [32]. Therefore, it is reasonable that associated symptoms may contribute to headache chronification and worsening of headache-related disability.

On the other hand, MHG headache profile was quite different from the other groups, and scored the worst outcome after facemask exposure. Indeed, MHG presented a remarkable worsening of headache frequency mainly for $\mathrm{HD}$, while MD resulted non-significantly changed. Moreover, attack mean duration, AHS, and allodynia significantly worsened at $\mathrm{T} 1$. These findings reflect different biology of migraine which could be considered a disorder of brain sensory processing [27]. Thus, facemask could exert a sustained mechanical stimulus triggering headache attacks. Furthermore, it might determine changes in central nervous system through alterations in nociceptive thresholds and alterations in pain pathways producing peripheral and central sensitization. Once sensitization established, trigeminovascular neuron activation becomes stimulusindependent and maintains itself in the absence of sensory input later on [33]. Central sensitization is crucial for migraine progression [34]. Cutaneous allodynia could be considered the hallmark of central sensitization, and it has already been reported as an independent predictor of migraine chronification. According to literature data and in line with our results, cutaneous allodynia is associated with higher frequency of migraine and longer migraine duration [35].

The strengths of this study could be considered sample size, use of validated scales and measures to assess participants' clinical outcomes, and high level of participants' education ensuring accuracy and reliability of information recorded through the questionnaire. We also acknowledge several limitations in our work. As first limitation, participants were not asked if their headache started within $1 \mathrm{~h}$ after wearing facemask or if they experienced headache relief within $1 \mathrm{~h}$ after unmasking, making difficult the hypothetical diagnosis of both external-compression (4.6.1) and external-traction (4.6.2) headache according to the ICHD-3 criteria [14]. Our self-administered questionnaire only included two closeended questions on headache attacks' duration and number of daily hours wearing facemask. The majority $(79.5 \%)$ of NHG-DN respondents experienced a mean duration of the headache attacks $<12 \mathrm{~h}$; the remaining $20.5 \%$ reported a longer duration, regardless of facemask donning time (Table 1). Moreover, a multivariate (multiple) linear regression analysis did not reveal a significative relationship between the variable "hours wearing facemask" and the outcome measure "headache attack mean duration."

As previously mentioned, de novo PPE-associated external-compression headache and exacerbation of pre-existing headache disorders have been already described as linked to the use of close-fitting N95 facemask alone or in combination with protective eyewear [13]. Because the present study was performed during the Italian phase II, the majority (74.2\%) of healthcare workers reported using as PPE only the surgical facemask, a loose-fitting disposable exerting less pressure against head and less likely to cause external-compression or external traction headache. The majority of subjects developing de novo headache (38/44 of NHG-DN group) declared wearing the surgical facemask. 
This study was performed among healthcare providers based predominantly in low-risk areas, making the study sample maybe not inclusive of frontline healthcare providers in high-risk areas. Participants did not fill headache diary: clinical data such as headache frequency, pain severity, associated symptoms, and pain killers' intake have been retrospectively collected using a self-administered questionnaire. Factors other than facemask type and elastic head straps, such as psychological stress, sleep disturbances, and change in lifestyle (i.e., dehydration and skipping meals), were not included in the study. Hence, we recognize that different factors might have triggered headache, mainly in frontline healthcare providers working in high-risk areas and suffering with a pre-existing primary headache disorder. However, our questionnaire was administered during phase II, when the number of COVID-19 cases and, consequently, the pressure on the national healthcare system were remarkably reduced; therefore, we speculate a minor impact of the aforementioned factors.

\section{Conclusion}

This study aims to clarify the link between extensive facemask wearing and headache variations among Italian healthcare providers, in a setting of low-medium risk of exposure to SARSCoV-2. Assuming that facemasks' wearing by healthcare workers remains a milestone of protection against spreading of a lifethreatening disease as COVID-19, our data showed de novo headache appearance in a proportion of subjects which was headache free at baseline, and an exacerbation of a pre-existing primary headache disorder, particularly for migraineur subjects.

Supplementary Information The online version contains supplementary material available at https://doi.org/10.1007/s10072-021-05075-8.

Data availability The data that support the findings of this study are available on request from the corresponding author.

Code availability Not applicable.

\section{Declarations}

Ethical approval Approval was obtained from the ethics committee of Magna Graecia University of Catanzaro. The procedures used in this study adhere to the tenets of the Declaration of Helsinki.

Informed Consent Written informed consent was obtained from each participant.

Consent to participate Written informed consent was obtained from all participants.

Consent for publication Not applicable.

Conflict of interest The authors declare no competing interests.

\section{References}

1. Zhu N, Zhang D, Wang W, Li X, Yang B, Song J, Zhao X, Huang B, Shi W, Niu P, Zhan F, Ma X, Wang D, Xu W, Wu G, Gao GF, Tan W, China Novel Coronavirus Investigation and Research Team (2020) A novel coronavirus from patients with pneumonia in China, 2019. N Engl J Med 382:727-733. https://doi.org/10.1056/ NEJMoa2001017

2. Huang C, Wang Y, Li X, Li X, Ren L, Zhao J, Zhang L, Fan G, Xu J, Gu X, Cheng Z, Yu T, Xia J, Wei Y, Wu W, Xie X, Yin W, Li H, Liu M, Xiao Y, Gao H, Guo L, Xie J, Wang G, Jiang R, Gao Z, Jin Q, Wang J, Cao B (2020) Clinical features of patients infected with 2019 novel coronavirus in Wuhan, China. Lancet 395:497-506. https://doi.org/10.1016/S0140-6736(20)30183-5

3. Wu Z, McGoogan JM (2020) Characteristics of and important lessons from the coronavirus disease 2019 (COVID-19) outbreak in China: summary of a report of 72314 cases from the Chinese center for disease control and prevention. JAMA 323(13):1239-1242. https://doi.org/10.1001/jama.2020.2648

4. Capobianchi MRM, Rueca F, Messina E, Giombini E, Carletti E, Colavita F, Castilletti C, Lalle E, Bordi L, Vairo F, Nicastri E, Ippolito G, Gruber CEM, Bartolini B (2020) Molecular characterization of SARS-CoV-2 from the first case of COVID-19 in Italy. Clin Microbiol Infect 26:954-956. https://doi.org/10.1016/j.cmi. 2020.03.025

5. Engineering CCfSSa (2021). Coronavirus COVID-19 global cases. https://gisanddata.maps.arcgis.com/apps/opsdashboard/index. html\#/bda7594740fd40299423467b48e9ecf6. Accessed Jan 07, 2021.

6. Remuzzi A, Remuzzi G (2020) COVID-19 and Italy: what next? Lancet 395:1225-1228. https://doi.org/10.1016/s0140-6736(20) 30627-9

7. DL $16 / 05 / 2020$ n.33, published on GU n.125 on $16 / 05 / 2020$. https://www.gazzettaufficiale.it/eli/gu/2020/05/16/125/sg/pdf. Accessed 30 Sep 2020

8. Wong JEL, Leo YS, Tan CC (2020) COVID-19 in Singaporecurrent experience: critical global issues that require attention and action. JAMA 323(13):1243-1244. https://doi.org/10.1001/jama. 2020.2467

9. Klompas M, Morris CA, Sinclair J, Pearson M, Shenoy ES (2020) Universal masking in hospitals in the COVID-19 era. N Engl J Med 382:e63. https://doi.org/10.1056/nejmp2006372

10. Liu Q, Luo D, Haase JE, Guo Q, Wang XQ, Liu S, Xia L, Liu Z, Yang J, Yang BX (2020) The experiences of health-care providers during the COVID-19 crisis in China: a qualitative study. Lancet Glob Health 8:e790-e798. https://doi.org/10.1016/s2214-109x(20) 30204-7

11. Rebmann T, Carrico R, Wang J (2013) Physiologic and other effects and compliance with long-term respirator use among medical intensive care unit nurses. Am J Infect Control 41:1218-1223. https://doi.org/10.1016/s2214-109x(20)30204-7

12. Lim ECH, Seet RCS, Lee KH, Wilder-Smith EPV, Chuah BYS, Ong BKC (2006) Headaches and the N95 face-mask amongst healthcare providers. Acta Neurol Scand 113:199-202. https://doi. org/10.1111/j.1600-0404.2005.00560.x

13. Ong JJY, Bharatendu C, Goh Y, Tang JZY, Sooi KWX, Tan BYQ, Teoh HL, Ong ST, Allen DM, Sharma VK (2020) Headaches Associated with Personal Protective Equipment - a cross-sectional study amongst frontline healthcare workers during COVID-19 (HAPPE Study). Headache 60:864-877. https://doi.org/10.1111/ head. 13811

14. (2018) Headache Classification Committee of the International Headache Society (IHS) The International Classification of Headache Disorders, 3rd edition. Cephalalgia; 38:1-211. https:// doi.org/10.1177/0333102417738202 
15. Dworkin RH, Turk DC, McDermott MP, Peirce-Sadner S, Burke LB, Cowan P, Farrar JT, Hertz S, Raja SN, Rappaport BA, Rauschkolb C, Sampaio C (2009) Interpreting the clinical importance of group differences in chronic pain clinical trials: IMMPACT recommendations. Pain 146:238-244. https://doi.org/10.1016/j. pain.2009.08.019

16. Yang M, Rendas-Baum R, Varon SF, Kosinski M (2011) Validation of the Headache Impact Test (HIT-6 ${ }^{\mathrm{TM}}$ ) across episodic and chronic migraine. Cephalalgia 31:357-367. https://doi.org/10. 1177/0333102410379890

17. Lipton RB, Bigal ME, Ashina S, Burstein R, Silberstein S, Reed ML, Serrano D, Stewart WF, American Migraine Prevalence Prevention Advisory Group (2008) Cutaneous allodynia in the migraine population. Ann Neurol 63:148-158. https://doi.org/10. 1002/ana.21211

18. Farrar JT, Young JP Jr, LaMoreaux L, Werth JL, Poole RM (2001) Clinical importance of changes in chronic pain intensity measured on an 11-point numerical pain rating scale. Pain 94:149-158. https://doi.org/10.1016/s0304-3959(01)00349-9

19. Radhonovich LJ, Perl TM, Davey V, Cohen H (2009) Preventing the soldiers of health care from becoming victims on the pandemic battlefield: respirators or surgical masks as the armor of choice. Disaster Med Public Health Prep 3(Suppl 2):S203-S210. https:// doi.org/10.1097/dmp.0b013e3181be830c

20. Shenal BV, Radhonovic LJ, Cheng J, Hogson M, Bender BS (2012) Discomfort and exertion associated with prolonged wear of respiratory protection in a health care setting. J Occup Environ Hyg 9:59-64. https://doi.org/10.1080/15459624.2012.635133

21. Krymchantowski AV (2010) (2010) Headaches due to external compression. Curr Pain Headache Rep 14:321-324. https://doi. org/10.1007/s11916-010-0122-x

22. Liang Z, Galea O, Thomas L, Jull G, Treleaven J (2019) Cervical musculoskeletal impairments in migraine and tension type headache: a systematic review and meta-analysis. Musculoskelet Sci Pract 42:67-83. https://doi.org/10.1016/j.msksp.2019.04.007

23. Fredriksen TA, Antonaci F, Sjaastad O (2015) Cervicogenic headache: too important to be left un- diagnosed. J Headache Pain 16:6. https://doi.org/10.1186/1129-2377-16-6

24. Barmherzig R, Kingston W (2019) Occipital neuralgia and cervicogenic headache: diagnosis and management. Curr Neurol Neurosci Rep 19:20. https://doi.org/10.1007/s11910-019-0937-8

25. Bush V, Jakob W, Juergens T, Schulte-Mattler W, Kaube H, May A (2006) Functional connectivity between trigeminal and occipital nerves revealed by occipital nerve blockade and nociceptive blink reflexes. Cephalalgia 26(1):50-55. https://doi.org/10.1111/j.14682982.2005.00992.x

26. Goadsby PJ, Lipton RB, Ferrari MD (2002) Migraine-current understanding and treatment. N Engl J Med 346:257-270. https://doi. org/10.1056/nejmra010917

27. Goadsby PJ, Holland PR, Martins-Oliveira M, Hoffmann J, Schankin C, Akerman S (2017) Pathophysiology of migraine: a disorder of sensory processing. Physiol Rev 97:553-622. https:// doi.org/10.1152/physrev.00034.2015

28. Baron R, Hans G, Dickenson A (2013) Peripheral input and its importance for central sensitization. Ann Neurol 74:630-636. https://doi.org/10.1002/ana.24017

29. Latremoliere A, Woolf CJ (2009) Central sensitization: a generator of pain hypersensitivity by central neural plasticity. J Pain 10:895926. https://doi.org/10.1016/j.jpain.2009.06.012

30. Buchgreitz L, Lyngberg AC, Bendtsen L, Jensen R (2008) Increased pain sensitivity is not a risk factor but a consequence of frequent headache: a population-based follow-up study. Pain 137: 623-630. https://doi.org/10.1016/j.pain.2007.10.023

31. Buchgreitz L, Lyngberg AC, Bendtsen L, Jensen R (2006) Increased prevalence of tension-type headache over a 12-year period is related to increased pain sensitivity. Cephalalgia 27:145152. https://doi.org/10.1111/j.1468-2982.2006.01248.x

32. Reed ML, Fanning KM, Serrano D, Buse DC, Lipton RB (2015) Persistent frequent nausea is associated with progression to chronic migraine: AMPP study results. Headache 55:76-87. https://doi.org/ 10.1111/head. 12450

33. Bigal ME, Lipton RB (2008) Concepts and mechanisms of migraine chronification. Headache 48:7-15. https://doi.org/10.1111/ j.1526-4610.2007.00969.x

34. Bernstein C, Burstein R (2012) Sensitization of the trigeminovascular pathway: perspective and implications to migraine pathophysiology. J Clin Neurol 8:89-99. https://doi.org/ 10.3988/jen.2012.8.2.89

35. Louter M, Bosker JE, van Oosterhout WPJ, van Zwet EW, Zitman FG, Ferrari MD, Terwindt GM (2013) Cutaneous allodynia as a predictor of migraine chronification. Brain 136:3489-3496. https://doi.org/10.1093/brain/awt251

Publisher's note Springer Nature remains neutral with regard to jurisdictional claims in published maps and institutional affiliations. 